\title{
Designing and Implementing a Distance Education Plan: A Case Study at a School in Portugal in Pandemic Context
}

\author{
Bruno Miguel F. Gonçalves \\ Polytechnic Institute of Bragança, Portugal
}

\begin{abstract}
.
Considering the epidemiological situation of the new coronavirus - COVID 19 in Portugal, the XXII Constitutional Government decided, in March 2020, to suspend all classroom teaching and non-teaching activities in all educational establishments in the national territory. Consequently, all Portuguese educational institutions had to adapt to the new educational reality, where technologies play a leading role in ensuring communication, interaction and collaboration between all stakeholders in the teaching-learning process. Naturally, this adaptation took time and was accompanied by several opinions and guidelines issued by the Ministry of Education and other responsible entities. In general, these guidelines aimed to ensure that all students continue to learn in a pandemic context, regardless of geographical and temporal barriers. One of the guidelines issued was the design, development and implementation of a Distance Learning Plan in each of the Portuguese schools. Thus, based on the case study methodology, we intend to demonstrate the process of designing and implementing a distance education plan in a school in Portugal. The plan was categorized into three main areas - technology, pedagogy, and content - and arise from the theoretical model Technological, Pedagogical and Content Knowledge (TPACK). This plan was developed based on the consultation of all educational agents in that school, but, in a special way, of the students and teachers who were the protagonists in the educational process. Participant observation, recorded in the researcher's diary, was also another instrument used that contributed to the design of the distance education plan. The results of the study suggest that the plan designed, despite the improvements that it naturally had to have during its implementation, was adequate for the realization of the process of teaching and learning at a distance in times of pandemic.
\end{abstract}

Keywords: Distance Education Plan, Pandemic Covid-19, Teaching-learning process, Technologies, TPACK. 